\title{
ON THE \\ AVERAGE VELOCITY \\ OF FLOW \\ OVER A MOVABLE BED
}

BY

SELIM YALIN *

Table of symbols.

$g$ acceleration due to gravity;

$\checkmark$ kinematic viscosity;

$\rho$ density of fluid;

$\rho_{s}$ density of bed material;

$\gamma_{s}$ specific weight of bed material in fluid;

$D$ a typical diameter of bed material (e.g. $D_{\max }, D_{50}$, etc.);

$h$ depth of uniform flow;

S slope;

$v$ average velocity of flow; $v_{*}=\sqrt{g \mathrm{~S} h}$ shear velocity;

$c=v / \nu_{*}$ friction factor;

$q=v . h$ discharge per unit width;

$k_{s} \sim \mathrm{D}$ "sand-roughness";

$k$ roughness of movable bed;

$\Delta$ height of a sand-wave;

$\lambda$ length of a sand-wave;

$\psi$ angle of repose of bed material;

$\bar{c}$ friction factor of a rough rigid bed;

$w$ terminal velocity of a grain.

\section{Introduction.}

Observations show that the movement of bed material, due to dynamic action of flow, is commonly accompanied by ripples, a wave-like deformation of the surface of the mobile bed. Obviously the properties of the motion of a fluid on an undulating surface are not identical to those on a plane surface, and consequently the friction factor $c=$ (average velocity)/(shear velocity) cannot remain the same when an initially plane surface of the bed turns into an undulating one. The question how the quantity $c$ depends on the shape and size of the sand waves and thus on the characteristic parameters defining a flow-phenomenon on

* Hydraulics Research Station, Wallingford.

a movable bed is one of the most popular subjects of investigation of contemporary fluvial hydraulics. The purpose of the present paper is to suggest how, according to the requirements of the theory of dimensions, the experimental data has to be used in order to determine the friction factor $c$.

\section{Dimensionless variables of the phenomenon.}

Consider the case of a steady and uniform twodimensional flow of a real fluid with a free surface over a cohesionless movable bed. It is assumed that the following geometrical properties of the bed material are specified:

(i) The shape of grains;

(ii) The shape of the grain-size distribution curve. 
In this case the phenomenon is completely defined by the characteristic parameters:

$$
\nu, \rho, \rho_{s}, \mathrm{D}, h, \mathrm{~S}, g
$$

It is possible to replace any of the parameters (1) by any independent combinations in which they occur (see e.g. Ref. [1]). The substitution of $g$ and S by:

and:

$$
\gamma_{s}=\left(\rho_{s}-\rho\right) \cdot g
$$

yields:

$$
v_{*}=\sqrt{g \mathrm{Sh}}
$$

$$
\nu, \rho, \rho_{s}, \mathrm{D}, h, \Upsilon_{s}, b_{*}
$$

Hence any mechanical quantity related to the flow-phenomenon under consideration, must, in general, be a certain function of all seven characteristic parameters (4), therefore the expression for the average velocity of the flow $v=q / h$, must be :

$$
v=f_{v}\left(\nu, \rho, \rho_{s}, \mathbf{D}, h, \gamma_{s}, v_{*}\right)
$$

Since the functional relationship (5) represents a physical fact which does not depend on the choice of the units of measurement, then according to the $\pi$-theorem of the theory of dimensions this relation can be expressed in a dimensionless form as follows:

with:

$$
c=\frac{v}{v_{*}}=\mathrm{F}_{\perp}(\mathrm{X}, \mathrm{Y}, \mathrm{Z}, \mathrm{W})
$$

$\mathrm{X}=\frac{\mathrm{D} \cdot v_{*}}{\nu} ; \quad \mathrm{Y}=\frac{\rho \cdot v_{*}^{2}}{\gamma_{s} \cdot \mathrm{D}} ; \quad \mathrm{Z}=\frac{h}{\mathrm{D}} ; \quad \mathrm{W}=\frac{\rho}{\rho_{s}}$

Observe that a rough rigid bed can be considered as a special case of a mobile bed having $p_{s} \rightarrow \infty$ (i.e. extremely heavy grains). In this case $\mathrm{D} \sim k_{s}$ and:

$$
\mathrm{X}=\frac{k_{s} \cdot v_{*}}{\nu} ; \quad \mathrm{Z}=\frac{h}{k_{s}} ; \quad \mathrm{Y}=\mathrm{W}=0=\mathrm{const}
$$
thus:

$$
\bar{c}=\frac{v}{v_{*}}=\overline{\mathrm{F}}_{1}\left(\frac{k_{s} \cdot v_{*}}{\nu} ; \frac{h}{k_{\mathrm{s}}}\right)
$$

as one would expect.

If the amount of the bed material in suspension is negligible, then from the point of view of the flow, the mobility of the bed implies, only a variation in the geometry of the bed surfaces. In other words the expression for $c$ must not differ from that for a rigid bed if $k$ represents the roughness caused by ripples. Therefore assuming $k \sim \Delta$, for the case of fully developed turbulent motion, the following relation must also be valid:

$$
c=\frac{v}{v_{*}}=f\left(\frac{h}{\Delta}\right)
$$

Here the form of $f$ depends itself on the geometry of ripples and on the relative roughness of their

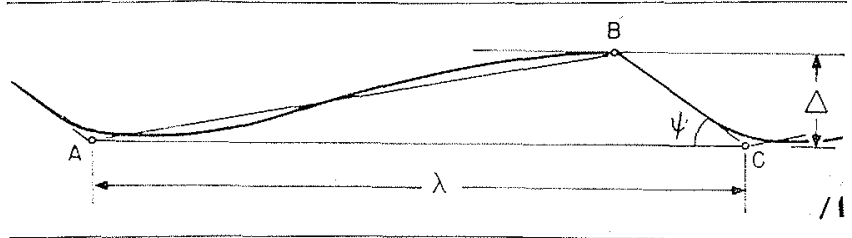

surfaces $h / k_{s} \sim Z$. The shape of the triangle ABC, approximating a ripple in Figure 1 , is completely defined by the angle $\psi$ and the ratio $\Delta / \lambda$. Thus (10) can be expressed a follows:

$$
c=\frac{v}{v_{*}}=\mathrm{F}_{2}\left(\frac{h}{\Delta} ; \frac{h}{k_{s}} ; \frac{\Delta}{\lambda} ; \psi\right)
$$

where, it can be assumed that, the form of $F_{2}$ does not depend any more on the geometry of the ripples nor on the roughness of their surfaces.

In spite of the different appearance (11) does not conflict with (6). For since $\Delta$ and $\lambda$ are the quantities related to the phenomenon:

$$
\begin{aligned}
& \frac{\Delta}{\mathrm{D}}=f_{\triangle}(\mathrm{X}, \mathrm{Y}, \mathrm{Z}, \mathrm{W}) \\
& \frac{\lambda}{\mathrm{D}}=f_{\lambda}(\mathrm{X}, \mathrm{Y}, \mathrm{Z}, \mathrm{W})
\end{aligned}
$$

whereas:

$$
\frac{h}{k_{s}} \sim Z \text { and } \psi \approx \text { const. (angle of repose). }
$$

From substitution of these values in (11) it follows that $F_{2}$ is in fact a function of $X, Y, Z$ and $W$ only; and thus (6) and (11), on principle, are identical.

In the following paragraph an attempt to derive theoretically an approximate form for the function $F_{2}$ is demonstrated.

\section{Form of the function $\mathrm{F}_{2}$.}

It is known in hydraulics that the head loss due to a contraction is very small compared with that of an expansion (see e.g. Ref. [2]). For example, the greatest part of the head loss caused by the sudden contraction of the rigid boundaries (Fig. $2 a$ )

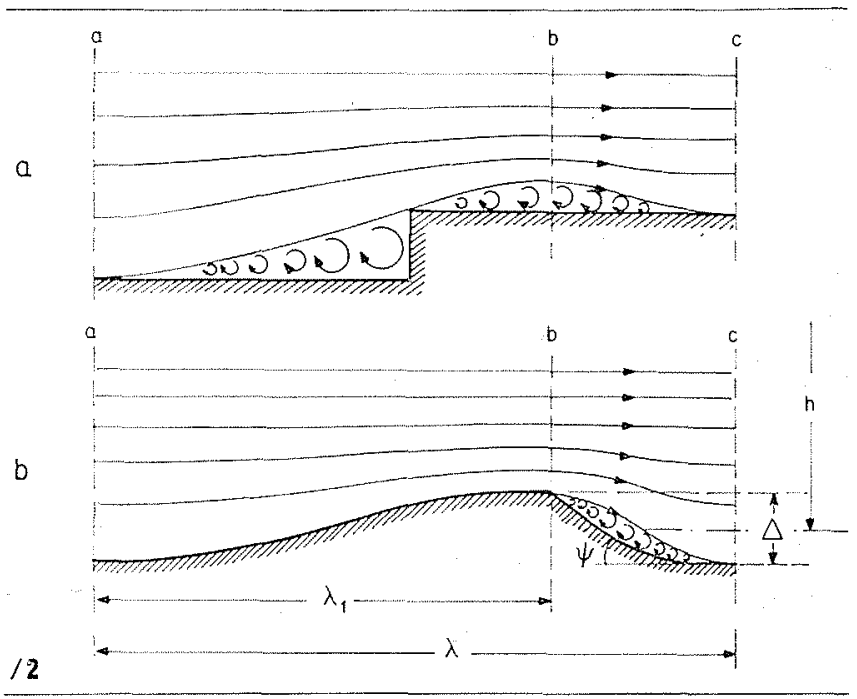

consists mainly of the head loss due to the expansion $b \rightarrow c$; the effect of the contraction $a \rightarrow b$ being negligible (Ref. [2]). Accordingly the head loss due to the presence of a ripple (Fig. $2 b$ ) can be assumed to be equal to that due to the expansion $b \rightarrow c$, plus the head loss due to the skin-friction along $a \rightarrow b$.

The head loss due to the expansion $b \rightarrow c$ can be expressed as follows:

$$
\zeta_{b c}=\alpha \frac{\left(v_{b}-v_{c}\right)^{2}}{2 g}
$$


whereas the condition of continuity yields:

$$
v_{b}\left(h-\frac{\Delta}{2}\right)=v_{c}\left(h+\frac{\Delta}{2}\right)=v h
$$

thus:

$$
\zeta_{b c}=\left(\frac{\Delta / h}{1-1 / 4(\Delta / h)^{2}}\right)^{2} \cdot \alpha \cdot \frac{v^{2}}{2 g}
$$

If, say,

$(\Delta / h) \leqslant 1 / 10$ then $0.997 \leqslant 1-1 / 4(\Delta / h)^{2} \leqslant 1$, i.e. the denominator of the multiplier in brackets is practically $\approx 1$; whereas for the usual values of the angle of repose $\psi, \alpha \approx 1$ (Ref. [3]). Thus (16) can well be approximated by:

$$
\zeta_{b c} \approx\left(\frac{\Delta}{h}\right)^{2} \frac{v^{2}}{2 g}
$$

Consequently the part of the energy gradient corresponding to the expansions $b \rightarrow c$ after each ripple length $\lambda$, is:

$$
\mathrm{S}_{1}=\frac{\zeta_{b c}}{\lambda}=\frac{1}{2} \cdot\left(\frac{\Delta}{h}\right) \cdot\left(\frac{\Delta}{\lambda}\right) \cdot \frac{v^{2}}{g h}
$$

whereas the part corresponding to the skin-friction along the distances $\bar{a} \bar{b} \approx \lambda_{1}$, is:

$$
\begin{gathered}
\mathrm{S}_{2}=\frac{\lambda_{1}}{\lambda} \cdot \frac{x^{2}}{\left[\ln \left(a \frac{h}{k_{s}^{-}}\right)\right]^{2}} \cdot \frac{v^{2}}{g h} \\
\left(\text { with } \frac{\lambda_{1}}{\lambda} \approx 1-\frac{\Delta}{\lambda} \cdot \operatorname{ctg} \psi\right)
\end{gathered}
$$

Thus :

$$
\mathrm{S}=\mathrm{S}_{1}+\mathrm{S}_{2}=\frac{1-(\Delta / \lambda) \sigma}{\left[\frac{1}{x} \ln \left(a \frac{h}{k_{s}}\right)\right]^{2}} \cdot \frac{v^{2}}{g h}
$$

and therefore:

$$
c=\frac{v}{v_{*}}=\frac{(1 / x) \ln \left[a\left(h / k_{s}\right)\right]}{\sqrt{1-(\Delta / \lambda) \sigma}}
$$

where:

$$
\sigma=\operatorname{ctg} \psi-\frac{1}{2} \frac{\Delta}{h} \cdot\left[\frac{1}{x} \ln \left(a \frac{h}{k_{s}}\right)\right]^{2}
$$

Here $x$ and $a$ are constants

$$
\left(x=0.4, a=e^{2.4}=11.00\right) \text { (Ref. [4]). }
$$

Thus $c$ is a function of $h / \Delta, h / k_{s}, \Delta / \lambda$ and $\psi$ only as predicted by (11). If there are no ripples,

$$
\text { i.e. } \Delta=0 \text {, }
$$

then (21) reduces to:

$$
\bar{c}=\frac{v}{v_{*}}=\frac{1}{x} \ln \left(a \frac{h}{k_{s}}\right)
$$

as one would expect. From (21) and (23) it follows that the relation between the friction factors for a mobile bed $c$ and for a rigid bed (having the same roughness $\left.k_{s}\right)^{*} \bar{c}$ is :

$$
\frac{\bar{c}}{c}=\sqrt{1-\frac{\Delta}{\lambda} \cdot\left(\operatorname{ctg} \psi-\frac{\Delta}{h} \vec{c}^{2}\right)}
$$

(It seems that it is not possible to obtain $c$ from $c$ by a simple multiplier, as has been assumed by many authors.)

Figure 3 illustrates the result of the experimental

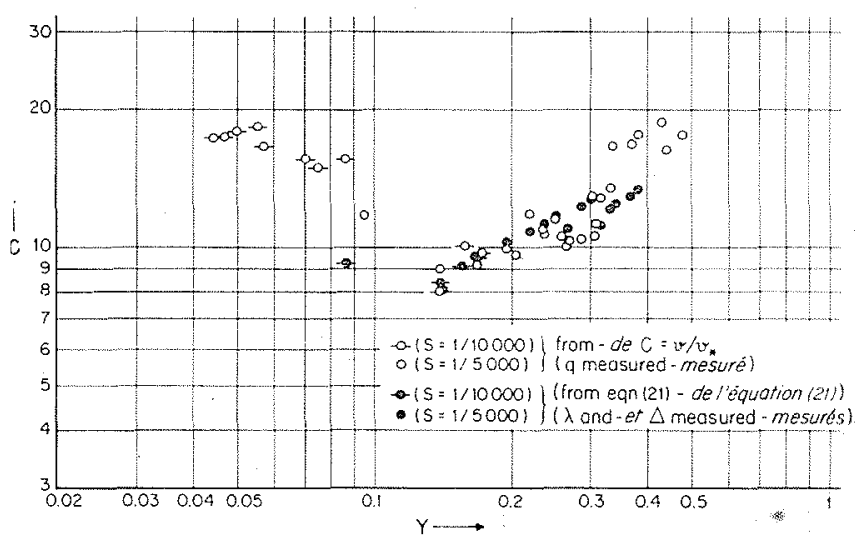

$/ 3$

check of the theoretically derived form (21). The measurements were carried out in a two-foot flume of the H.R.S.-Wallingford; the mobile bed consisted of polystyrene grains of equal shape and size $\left(\gamma_{s}=0.03 ; D=1.35 \mathrm{~mm}\right)$. The ripple characteristics $\Delta$ and $\lambda$ were measured for various values of $h(h<\sim 20 \mathrm{~cm})$; the slope of the uniform flow $\mathrm{S}$ being $1 / 5000$ and $1 / 10000$. Assuming $k_{s} \approx \mathrm{D}$ and $\operatorname{ctg} \psi=1.60$ and using measured values for $\Delta$ and $\lambda$, the quantity $c$ was computed from (21) for various values of $h$. As seen from Figure 3 the values of $c$ given by (21) show a satisfactory agreement with those obtained directly from the measurements of the flow-discharges $q$, i.e. from $c=q /(h \sqrt{g} h \mathrm{~S})$. (The actual water depths $h$, which were always less than $1 / 3$ of the width of the flume $(60 \mathrm{~cm})$, were reduced into those of the two-dimensional flow according to the method given by H.A. Einstein in Ref. [5], Appendix II.)

\section{Experimental values of $c$ for (water + sand).}

The form (21) shows how $c=v / v_{*}$ depends upon the properties of the ripples which are themselves the functions of $\mathrm{X}, \mathrm{Y}, \mathrm{Z}$ and $\mathrm{W}$. Thus $c$ can be considered directly as a certain function of $\mathrm{X}, \mathrm{Y}$, $Z$ and $W$. This fact is expressed by (6).

Observe that the consideration of $\mathrm{X}, \mathrm{Y}, \mathrm{Z}$ and $\mathrm{W}$ is equivalent to that of:

$$
\xi=X^{2} / Y ; \quad \eta=Y / Z ; \quad X ; \quad W
$$

and thus (6) can be replaced by:

$$
c=\frac{v}{v_{*}}=\mathrm{F}_{3}(\xi ; \eta ; \mathrm{Y} ; \mathrm{W})
$$

Although (6) and (26) are, mathematically considered, equivalent; from the practical point of view, (26) is more convenient. For, both:

$$
\xi=\gamma_{s} D^{3} / \rho v^{2} \text { and } W=\rho / \rho_{s}
$$

do not depend on the hydraulical properties (they do not involve $h, \mathrm{~S}$ or $v_{*}$ ) and therefore if the fluid and bed material are specified they remain constant. The hydraulic state of the flow-phenomenon 


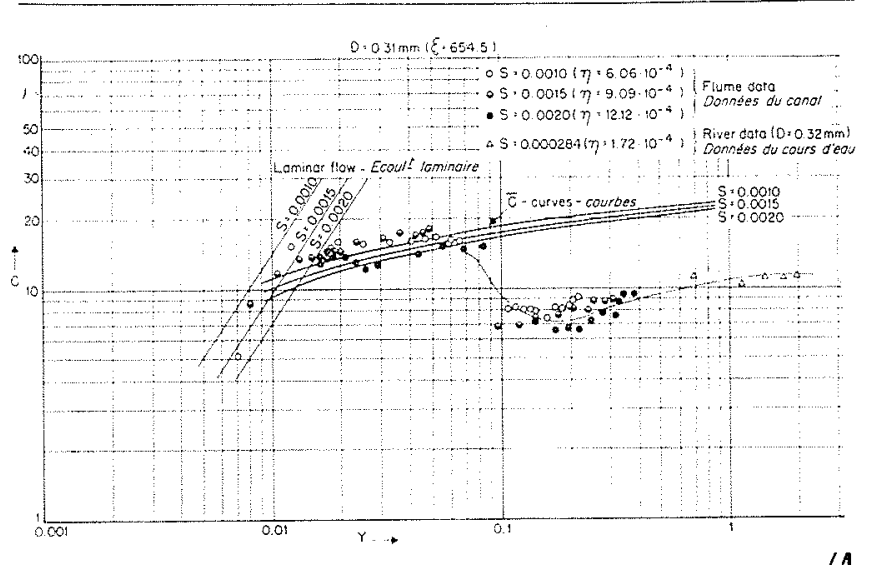

$/ 4$
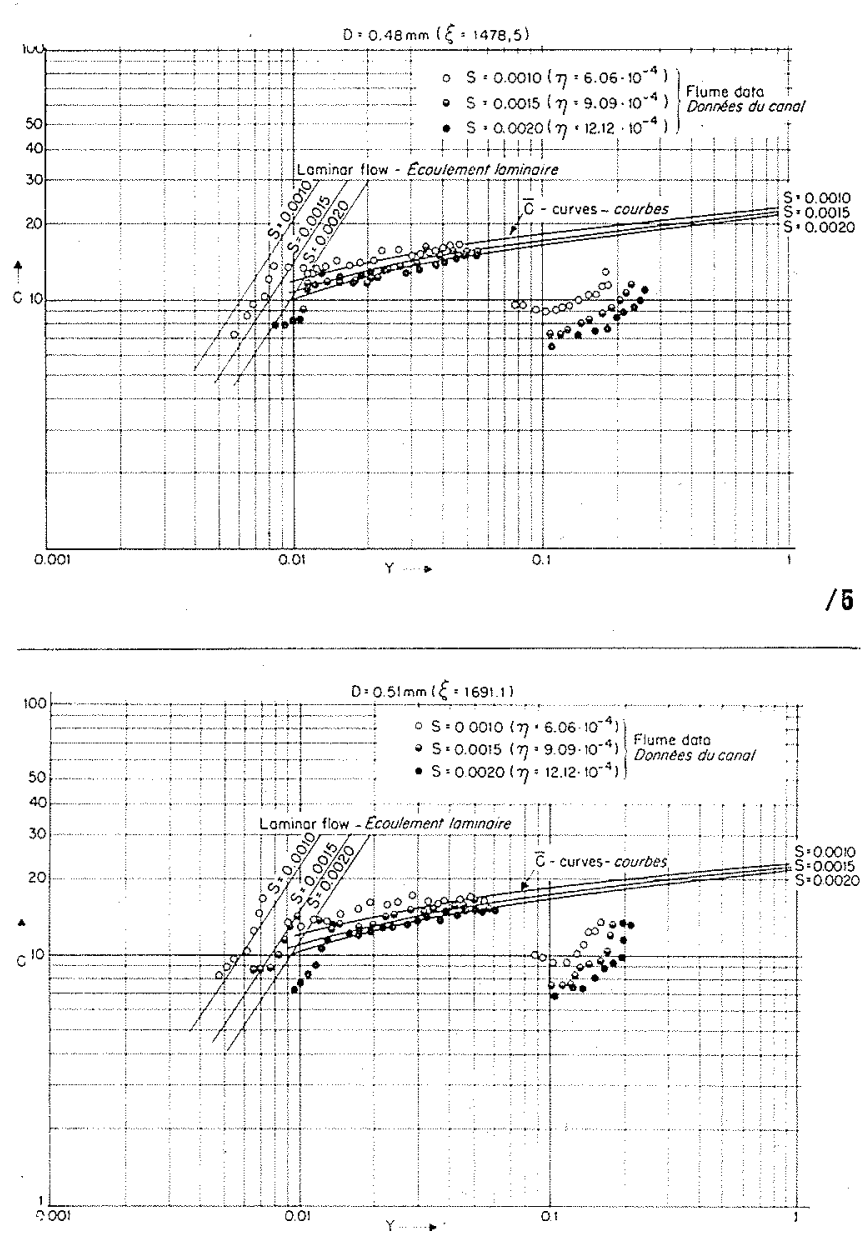

16

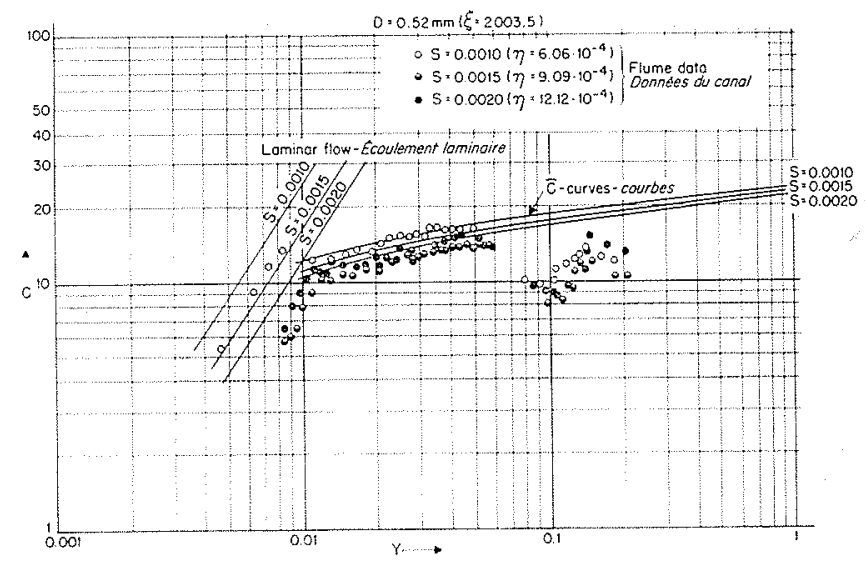

is reflected by $\eta=\left(\gamma / \Upsilon_{s}\right) . S$ and $Y=\rho v_{*}^{2} / \Upsilon_{s} D$ only.

Suppose now that it is intented to determine the form of the function $\mathrm{F}_{3}$ experimentally for (water + sand), i.e. for:

$$
\rho=101.70 \mathrm{~kg} \cdot \mathrm{s}^{2} \cdot \mathrm{m}^{-4}, \nu=1.01 .10^{-6} \mathrm{~m}^{2} / \mathrm{s}
$$

and $\gamma_{s}=1.65$.

In this case:

$$
\left.\begin{array}{rl}
\mathrm{W} & =1 / 2.65=\text { const. } \\
\xi & =16180 \mathrm{D}^{3} \quad[\mathrm{D} \text { in }(\mathrm{mm})] \\
\eta & =0.606 \mathrm{~S} \\
\mathrm{Y} & =0.606 \mathrm{Sh} / \mathrm{D}
\end{array}\right\}
$$

and $c$ reduces into a function of three variables only:

$$
c=\mathrm{F}_{4}(\xi ; \eta ; \mathrm{Y})
$$

Obviously the form of $\mathrm{F}_{4}$ depends on the constant value of $W$ and, theoretically, must change if $W$ changes. If $\mathrm{D}=$ const., i.e. a certain sand is selected, then $\xi=\overline{\text { const }}$ also and $c$ varies as a function of $\eta$ and $Y$ only:

$$
c=\mathrm{F}_{4}(\operatorname{const} ; \eta ; \mathrm{Y})
$$

and can be represented by a family of curves, having, say, $Y$ as abscissa, $c$ as ordinate and $\eta$ as parameter. In this case a certain curve corresponds to a certain value of $\eta$ (i.e. certain value of slope $S$ ). To another grain size $D$, i.e. to another constant values of $\xi$ corresponds another family of curves. Hence, if from measurements carried out for various grain sizes such families of curves are obtained then the totality of these families represents an experimental solution of the problem, i.e. the function $F_{4}$ is experimentally determined.

The experimental points on Figures 4-9 represent the curve-families (29) for the following values of $D$ (computed from the data in Ref. [6]) :

\section{$0.31 ; 0.48 ; 0.51 ; 0.52 ; 0.54 ; 0.59 ;(\mathrm{mm})$}

The corresponding $\xi=\overline{\text { const }}$ values are:

$$
\begin{array}{ccc}
654.5 ; & 1478.5 ; & 1691.1 ; \\
2003.5 ; & 3463.4 ; & 4401.0 .
\end{array}
$$

The grain-size distribution curves of the bed materials above have the same S-like shape (see Ref. [6]): the grain size $\mathrm{D}$ being chosen as $\mathrm{D}=\mathrm{D}_{50}$. If the shape of the grain-size distribution curve varies; then theoretically, the corresponding family of curves (29) must also vary even if the value of $D_{50}$ remains the same.

$\bar{c}$ - curves on Figures $4-9$ represent the values of the friction factor for the case of a rigid bed (see footnote ${ }^{*}$ ) as given by the logarithmic form

$$
\frac{u_{\max }}{v_{*}}=\frac{1}{x} \ln \mathrm{Z}+\mathrm{B}=\frac{1}{x} \ln \frac{\mathrm{Y}}{\eta}+\mathrm{B}
$$

and by relation:

$$
\bar{c}=\frac{u_{\max }}{v_{*}}-2.50
$$

where $B$ is a certain function of $X=\sqrt{\xi Y}$ given by Figure 20-20 in Ref. [4].

(See for (30) and (31) Ref. [4] chapt. XX.) $\vec{c}$-curves for laminar flow were obtained from eqn (11.22) in Ref. [7]. 


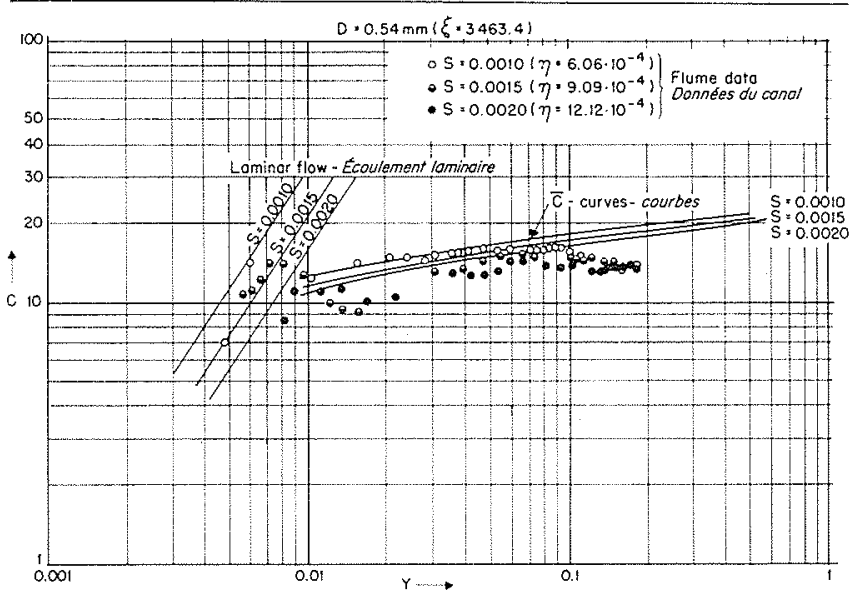

18

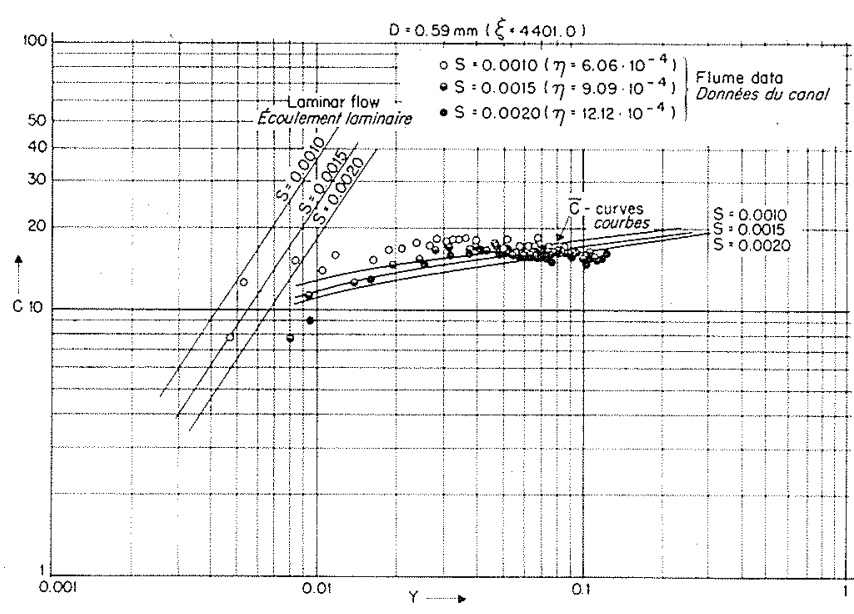

As seen from Figures 4-9.c-values given by experiment for a movable bed agree well with the theoretically obtained $\bar{c}$-curves when the values of $\mathrm{Y}$ are small (i.e. before the ripples are formed). As $Y$ increases, ripples form, and the $c$-values of the movable bed deviate considerably from $\bar{c}$-curves.

Figures 4-9 show that the experimental points corresponding to the various values of the slope $S$ (i.e. of $\eta$ ) are very close to each other, so close that the difference between the experimental curves $\mathrm{S}=$ const. is almost of the same order as the scatter due to the errors of measurement, i.e. the variation of $c$ with $\eta$ seems to be considerably weaker than the variation with $\mathrm{Y}$. On the other hand the paths formed by experimental points change considerably from one Figure to another, i.e. if $\xi$ varies. Hence it is possible to conclude that $\xi$ and $Y$ more important variable than $\eta$ (at least within the scope of the experiments plotted on Figures 4-9).

As seen from (25) $Z$ is involved in $\eta$ only. Thus to state that " $\eta$ is unimportant" means automatically that " $Z$ is unimportant" $[$ see $(7)] * *$.

Consider now the combination W. Suppose that the influence of $W$ is also negligible in comparison with $\xi$ and $Y$. If this assumption is correct, then, two flows flowing on different bed materials, i.e. having different values of $W$, must have the same, or nearly the same, values of $c$ if their values of $\xi$ and $Y$ are equal and their less important combinations $\eta$ are of the same order. $W=1 / 2.65 \mathrm{for}^{\circ}$ sand differs considerably from $W=1 / 1.03$ for polystyrene used in the experiments at H.R.S. The $\xi$-value of this polystyrene was $\xi=596.55$ whereas the $\xi$-value of the sand $D_{50}=0.347 \mathrm{~mm}$ (Sand No.6 in Ref. [6]) is $=676.30$ ). Since the $\xi$ values for both materials are of the same order, the $c$-values of the sand $\mathrm{D}_{50}=0.347 \mathrm{~mm}$ can be plotted versus $Y$ together with those of the polystyrene on Figure 10. As seen from Figure 10 the $c$-values

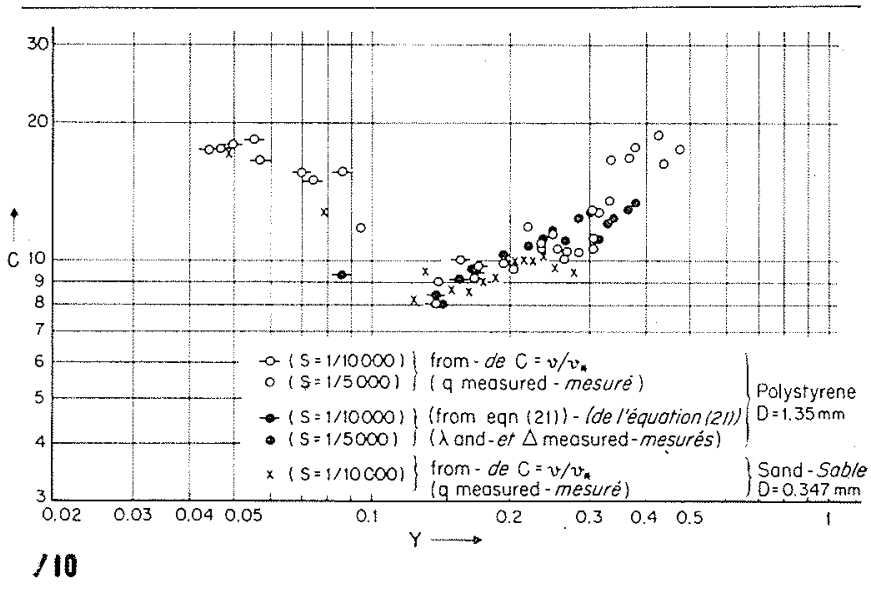

for both materials are of the same order (if $\xi$ and $Y$, i.e. if $X$ and $Y$ are the same) and thus the influence of $W$ can be neglected.

\section{General remarks.}

Since the flow-phenomenon studied in this paper is defined by seven independent mechanical quantities, according to the theory of dimensions the dimensionless quantity $c$ must be a function of four dimensionless variables $X, Y, Z, W$. However the theory of dimensions is not able to provide the form of such a function. On the other hand depending on the form of this function, $c$, may vary to a greater extent with some of the variables and to a lesser extent with others. Therefore if the consideration of some variables can be omitted, this is a purely practical decision and does not mean that the theory of dimensions provides the wrong number of variables. Consequently the statement that " $Z$ and W can be neglected" (within the scope of the experimental data used) does not imply that " $c$ does not depend on $Z$ and $W$ ".

In Ref. [8] it is assumed that the "irregularities on the bed surface" (ripples) and consequently $c$ is a function of the Einsteinian function $\Psi$ only. Since $\Psi$ is nothing else but the reciprocal of $Y$ (i.e. $\Psi=1 / Y$ ) the method given in Ref. [8] assumes, in terms of this paper, that $c$ is a function of $Y$ only. Apparently such a consideration is too simple. Indeed this method does not cover all the practical cases it purports to do. For example the Figures 7,2 and 7,3 in Ref. [9] show distinctly how

* Attention is drawn to the fact that the points, corresponding to the river-data (from Ref. [12]), in Figure 4 , form a natural extension of the path formed by the points of the flume-data; in spite of the much larger values of the riverdepths $(1.28 \mathrm{~m} \leqslant h \leqslant 3.63 \mathrm{~m} \approx 12 \mathrm{ft})$ and smaller value of the river-slope $(\mathrm{S}=0.000284)$. This confirms once more, that is, not $h$ and $\mathrm{S}$ separately, but the product $h . \mathrm{S}$ (i.e. $v^{2}=g h \mathrm{~S}$ ) which matters. Consequently the combinations involving $h$ and $S$ separately (i.e. $\eta$ and $Z$ ) must be less important than those involving $v_{*}$ (i.e. $\mathrm{X}$ and $\mathrm{X}$ ). 
the theoretical curves given by the method of Ref. [8] disagree with the results of the measurement.

In a more recent work-Ref. [10] a mathematical form for $c$ is determined (eqn (9) in Ref. [10]). Using the notations of the present paper eqn (9) in Ref. [10] can be written as follows:

$$
\left(\frac{\mathrm{Y}}{\mathrm{Z}}\right)^{0.15} \frac{c}{(\mathrm{~W}-1)^{0.85}}=\left(a_{1} \frac{w}{v_{*}} \mathrm{X}+a_{2} c^{2}\right)^{1.85}
$$

(with $a_{1}, a_{2}$ consts).

Thus $c$ is given as $c=f\left(\mathrm{X}, \mathrm{Y}, Z, W, w / v_{*}\right)$. But as proved in Ref. [11] $w / v_{*}$ cannot be an independent variable if $X$ and $Y$ are given. For:

$$
w / v_{*}=\varphi(\mathrm{X}, \mathrm{Y}) \text {. }
$$

Therefore $c=f[X, Y, Z, W, \varphi(X, Y)]$; i.e. according to Ref. [10] $c$ is a function of $X, Y, Z, W$ only, which agrees completely with the considerations of the present paper. However it is not intended to discuss whether the mathematical form, connecting $X, Y, Z, W$ in eqn (9) of Ref. [10], can also be correct.

\section{Acknowledgement.}

The Author wishes to acknowledge the work of Mr. B. A. Say, Assistant Experimental Officer, in carrying out all the numerical calculations. This study is published with the permission of the Director of Hydraulics Research.

\title{
References.
}

[1] L.I. Sedov. - Similarity and Dimensional Methods in Mechanics. Infosearch Limited, London, 1959.

[2] N.I. Pavlovskir, - Collected Works. Vol. 1, Academy of Sciences of the U.S.S.R., Moscow-Leningrad, 1955.

[3] I. E. IDexchin. - Hydraulic Losses. Gros. En. Izd., Moscow, 1954.

[4] H. Schlichting. - Boundary Layer Theory. McGrawHill Book Company Inc., New York, Toronto, London, 1960.

[5] H. A. Einstein. - Formulas for the Transportation of Bed Load. Trans. A.S.C.E., vol. 107, pp. 561-577, 1942.

[6] U.S.W.E.S. expts. - Paper No. 17, Studies of River Bed. Materials under Movement, with special reference to the lower Mississipi River, 1935.

[7] N.J. Kotschin, I. A. Krbet and N.W. Rose. - Theoretische Hydromechanik. Band 2, Akademie-Verlag, Berlin, 1955.
[8] H. A. Einstein and N.L. Barbarossa. - River Channel Roughness. Trans. A.S.C.E., vol. 117, pp. 1121-1146, 1952.

[9] V.A. VANON, N.H. Brooks and J.F. Kennedy. -- Lecture Notes on Sediment Transportation and Channel Stability. California Inst. of Technology, Report No. KH-R-1, Pasadena, Calif., 1961.

[10] D. B. Simons and E. V. Richardson. - Resistance to Flow in Alluvial Channels. Proc. A.S.C.E, vol. 86, HY5, 1960.

[11] M.S. Yalin. - An Expression for Bed Load Transportation. Proc. A.S.C.E., vol. 89, HY3, 1963.

[12] L. B. Leopold and T. Mapdock. - The Hydraulic Geometry of Stream Channels and some Physiographic Implications. U.S.G.S. professional paper 252, Washington, 1953.

\section{Résumé}

Vitesse moyenne d'un écoulement sur fond mobile

\author{
par M. Selim Yalin
}

\section{INTRODUCTION}

L'un des problèmes d'actualité de l'hydraulique fluviale est celui de l'influence des ondulations d'un lit alluvionnaire sur les pertes de charge de l'écoulement. L'auteur se propose de déterminer, à partir de considérations d'analyse dimensionnelle, les paramètres à adopter pour l'étude expérimentale de ce problème.

\section{Variables sans dimensions du phénomène :}

La vitesse moyenne $v$ de l'écoulement est fonction des sept paramètres définissant le fluide (viscosité cinématique y et masse volumique $\rho$ ), le matériau de fond (masse volumique $\rho_{s}$ et diamétre D), et l'écoulement (tirant d'eau $h$, pente $S$ et accélération de la pesanteur $g$ ), ou encore des paramètres dérivés $y, \rho, ?$, D, $h$,

$$
\gamma=\left(\rho_{s}-\rho\right) g \quad \text { et } v_{*}=\sqrt{g S h}
$$

Selon le théoreme des $\Pi$, le coefficient de frottement $c=v / v_{*}$ est alors fonction des quatre variables sans dimensions $X, Y, Z$ et $W$ (équ. 7 ).

Dans le cas d'un lit fixe plat et rugueux, $c$ est seulement fonction de $\mathrm{X}$ et $Z$, puisqu'on peut considérer que ce cas correspond à $o_{s}$ et $\gamma_{s} \rightarrow \infty$. La hauteur de rugosité $k_{s}$ est le diamètre caractéristique des grains de matériau. On obtient alors la relation $(9)$.

Quand le fond est ondulé, la hauteur de rugosité à prendre en compte est la hauteur des rides ou dunes; la forme de l'ondulation est définie d'autre part par l'angle de repos sous l'eau du matériau $\downarrow$ et la cambrure $\Delta / \lambda$ (fig. 1). Le coefficient de frottement $c$ est donc une fonction $F_{2}$ des paramètres $h / \Delta, h / k_{s}, \Delta / \lambda$ ét $\psi$ (équ. 11). 


\section{Forme de la fonction $\mathrm{F}_{2}$ :}

L'auteur détermine le coefïicient de frottement $c$ sur le fond à partir des pertes de charge de l'écoulement, lesquelles se subdivisent en :

- pertes de charge à la Borda au passage de la crête des dunes (fig. 2, équ. 17);

- pertes de charge par frottement sur la face amont des dunes (équ. 19).

L'expression finale de c est donnée par la relation (21).

Les valeurs de $c$ calculées par cette formule sont en bon accord avec celles déterminées en partant des valeurs expérimentales de $v / v_{*}$ (fig. 3), pour les essais en canal effectués au Laboratoire de Wallingford.

\section{Valeurs expérimentales de $c$ (eau + sable) :}

Le coefficient $c$ est fonction des paramètres $X, Y, Z$ et $W$, c'est-à-dire encore de $: \xi=X * / Y, \eta=Y / Z, Y$ et $W$. Le paramètre $\xi=\gamma_{g} \mathrm{D}^{*} / \varphi^{\vartheta^{2}}$ est pratique, car il est indépendant de l'écoulement.

Les figures 5 a 9 indiquent les résultats obtenus avec du sable ( $W=$ Cte), pour diverses granulométries $(\xi$ variable). Les valeurs expérimentales de $c$ sont très voisines des valeurs de $c$ calculées à partir de la loi de vitesse a la paroi de Prandtl, quand il n'y a pas de dunes. L'influence de la pente $S$ (c'est-à-dire de $\eta$ ) est négligeable, compte tenu des erreurs de mesure; par contre, l'allure des courbes dépend beaucoup de $\xi$.

Pour deux matériaux avec $\eta=\mathrm{S}\left(\gamma / \gamma_{\mathrm{s}}\right)$ voisins, les valeurs expérimentales de $c$ correspondant a des $\xi$ et $Y$ égaux sont très proches (voir fig. 10); le paramètre $W=\rho / \rho_{s}$ n'a donc pas d'influence très marquée.

\section{REMARQUES GÉNÉRALES :}

Les paramètres $Z$ (ou $\eta$ ) et W peuvent être négligés, du moins dans le domaine expérimental envisagé; ce qui ne signifie pas néanmoins que le coefficient $c$ soit indépendant de ces deux variables.

Einstein (réf. 8) supposait en fait que $c$ ne dépendait que de $\mathrm{Y}$; la divergence entre ses résultats théoriques et expérimentaux tient à cette hypothèse.

L'expression établie par Simons et Richardson (réf. 10) peut se mettre sous la forme $c=f\left(\mathrm{X}, \mathrm{Y}, \mathrm{Z}, \mathrm{W}, w / v_{*}\right)$, $w$ étant la vitesse de chute du grain. Comme $w / v_{*}$ ne dépend que de $\mathrm{X}$ et $\mathrm{Y}$, on est donc ramené à une fonction des quatre paramètres proposés par l'auteur. 